\title{
Medicalização da Educação: análise sobre os trabalhos apresentados no Fórum de Medicalização
}

\author{
Cristina Miyuki Hashizume* \\ Etiene Carolina Mattos Rainha** \\ Pâmela Thaís Magalhães Reis ${ }^{* * *}$ \\ Raquel Arminda Sória dos Santos ${ }^{* * * *}$
}

\section{Resumo}

A lógica de explicações dos problemas de aprendizagem segue pressupostos biológicos que estão atrelados a evidências físicas e orgânicas e pressupõem cura por meio de intervenção nesse âmbito. Tal prática, nas escolas, leva a um aumento na frequência de queixas escolares que chegam aos serviços públicos e particulares de saúde. $\mathrm{O}$ aumento significativo desses encaminhamentos é preocupante e foi o motivador de nosso artigo, que tem como objetivo analisar teórica e metodologicamente os resumos e trabalhos completos dos Anais do IV Seminário Internacional "A Educação Medicalizada: desver o mundo, perturbar os sentidos" (realizado em 2015), trazendo uma discussão sobre as relações entre medicalização, inclusão e os Direitos Humanos. Esse levantamento bibliográfico identificou 24 trabalhos (entre resumos e trabalhos completos). Esse levantamento faz parte de pesquisa em andamento que problematiza o modo como tem sido visto o problema de aprendizagem, que pretende compreender como se dá o processo de medicalização no registro dos prontuários das crianças em escolas municipais na região do ABCD. Como análises do estudo

* Profa. dra. do Programa de Pós Graduação em Educação da UMESP. cristina.hashizume@metodista.br

** Graduanda de Pedagogia- UMESP. etiih_@hotmail.com

*** Graduanda de Pedagogia - UMESP.pammagalhaes19@gmail.com

***** Psicóloga, Graduanda de Pedagogia - bolsista de Iniciação Científica- UMESP. quelsoria@gmail.com 
bibliográfico temos as preocupações dos autores dos trabalhos em categorizar os referenciais teóricos, classificação da abordagem (se é empírica ou revisão de literatura) e as propostas de intervenção frente ao problema.

Palavras-chave: Medicalização. Empiria. Pesquisas com problema de aprendizagem. Direitos Humanos.

\section{Medical education: Analysis of articles presented in the Medicalization Forum}

\section{Abstract}

The learning problem's logic explanations follows biological assumptions that are linked to physical and organic evidence and presuppose cure through intervention in this area. Such practice in schools leads to an increase in the frequency of school complaints that come to public and private health services. The significant increase in these referrals is worrisome and was the motivator of our article, which aims to analyze abstracts and papers of the IV International Seminar "Medicalized Education: unveiling the world, disturbing the senses" (2015). This bibliographic survey identified 24 papers (including abstracts and full papers). This survey is part of ongoing research that problematizes the learning problem, which aims to understand how the medicalization process takes place in the children's stories in municipal schools in the ABCD region. As analysis of the bibliographic study, we have the author's concerns in categorizing the theoretical references, classification of the approach (whether it is empirical or literature review) and intervention proposals facing the problem.

Keywords: Medicalization. Empiricism. Learning problem's research. Human Rights.

\section{Educación médica: Análisis de artículos presenta- dos en el Medicalization Forum}

\section{Resumen}

La lógica de las explicaciones de los problemas de aprendizaje sigue suposiciones biológicas que están vinculadas a la evidencia física y orgánica y presuponen la curación a través de la intervención en esta área. Dicha práctica en las escuelas lleva a un aumento en la frecuencia de quejas escolares que llegan a los servicios de salud públicos y privados. El aumento significativo de estas referencias es preocupante y fue el motivador de nuestro artículo, cuyo objetivo es analizar resúmenes y trabajos completos 
de los Anales del IV Seminario Internacional "Educación Medicalizada: desvelar el mundo, perturbar los sentidos" (realizado en 2018). Esta búsqueda bibliográfica identificó 24 trabajos (incluidos resúmenes y trabajos completos). Esta búsqueca es parte de una investigación en curso que problematiza la forma en que se ha visto el problema de aprendizaje, cuyo objetivo es comprender cómo se lleva a cabo el proceso de medicalización en los registros de los niños en las escuelas municipales de la región de el ABCD (cerca de la ciudad de São Paulo). Como análisis del estudio bibliográfico, tenemos las preocupaciones de los autores al clasificar las referencias teóricas, la clasificación del enfoque (ya sea empírica o de revisión de la literatura) y las propuestas de intervención que enfrentan el problema.

Palabras clave: Medicalización. Empirismo. Investigación con problemas de aprendizaje. Derechos Humanos.

\section{Introdução}

Estudos empíricos com crianças em idade escolar têm demonstrado serem estas alvo de uma grande variedade de diagnósticos de doenças psicopatológicas, muitas vezes relacionadas à aprendizagem. Guarido (2010) ressalta que, nessa realidade, busca-se apenas tratar os sintomas apresentados pela criança por meio da medicação, sem dar a devida atenção a outros fatores presentes na realidade dela, nem às complexas manifestações singulares de cada história da criança analisada. A lógica de explicações dos problemas de aprendizagem segue pressupostos biologicizantes (anátomo-fisiológicos), sempre atrelados a evidências físicas e orgânicas e que pressupõem cura por intermédio da intervenção nesse âmbito. Para Meira (2012), essa associação entre transtornos neurológicos e dificuldades na aprendizagem tem feito parte do discurso de muitas escolas, o que leva a um aumento na frequência de queixas escolares que chegam aos serviços públicos e particulares de saúde. $\mathrm{O}$ aumento significativo desses encaminhamentos é preocupante, pois demonstra como "a compreensão de um fenômeno tão complexo quanto os problemas de escolarização, produzidos no interior de um sistema de ensino precarizado, é reduzida a dificuldades individuais, de caráter orgânico" (ANGELUCCI \& SOUZA, 2010, p. 7). 
Nosso artigo tratará das análises de resumos e trabalhos completos a partir dos Anais do IV Seminário Internacional "A Educação Medicalizada: desver o mundo, perturbar os sentidos" (realizado em 2018). Esse levantamento faz parte de pesquisa em andamento que problematiza o modo como tem sido visto o problema de aprendizagem, que pretende compreender como se dá o processo de medicalização no registro dos prontuários das crianças em escolas municipais na região do ABCD (SP) (MOISES, 2013).

A presente pesquisa problematizará a discussão a respeito da medicalização de alunos a partir da análise teórico-metodológica de trabalhos apresentados no Seminário Internacional ocorrido em 2015. Nosso problema de pesquisa se contextualiza no aumento de consumo de psicotrópicos em crianças em idade escolar e busca compreender as pesquisas realizadas sobre os impactos do uso de psicotrópicos em crianças com problemas de aprendizagem em situação oficialmente diagnosticada, ou não. O principal objetivo deste trabalho é mapear os trabalhos exibidos no IV Seminário Internacional "A Educação Medicalizada: desver o mundo, perturbar os sentidos" apresentado em Salvador-BA, em setembro de 2015 mostrando as diferentes abordagens acerca do tema, enfoques das pesquisas sobre medicalização. Também problematizaremos as questões decorrentes do uso de psicotrópicos em crianças em fase escolar; cartografaremos a lógica da produção, que subjaz o alto uso de medicamentos pelas vias oficiais do SUS e de atendimento complementar à saúde. Pelo número de trabalhos inscritos no referido Seminário, reconhecemos que há premente necessidade de se estudar o tema, a partir das intervenções e trabalhos desenvolvidos em diferentes localidades do Estado de São Paulo e no Brasil inteiro.

\section{A diferença e a necessidade de classificação}

A diferença sempre foi tida como um aspecto a ser exterminado do funcionamento socioinstitucional. Aquilo que difere da norma, do padrão, estatisticamente falando, também acaba por ser visto como uma reação à submissão às regras. E tanto a governa- 
mentalidade (Estado e instituições) quanto os indivíduos, em geral, se incomodam ao que foge à normalidade, dando-lhe um caráter de patologia e inadequação. Tanto a Psicologia como a Educação têm realizado amplos estudos em termos de Direitos Humanos e inclusão, a partir de um olhar comprometido com a garantia dos direitos e respeito à dignidade humana e seus impactos na autoestima e constituição da subjetividade do indivíduo diferente. A necessidade de normatizar, normalizar e controlar os corpos e as subjetividades desses diferentes é um objetivo importante para efeitos de governamentalidade social (NOZU, et al., 2013). Nesse sentido, mesmo que para nós pareça apenas um incômodo inocente com o diferente, estudos estruturais têm nos mostrado que a normatização de comportamentos envolve um projeto estratégico de controle de comportamentos e subjetividades, que pretende controlar vidas, dando-lhes certa regularidade e normatividade, processo esse, denominado por Foucault $(1977 ; 1997)$ como biopoder.

Patologizar o que não é recorrente (normal) é uma forma de se controlar os comportamentos desviantes e não subordinados que incomodam a gestão: governantes, professores em suas salas de aulas, chefes, instituições. Patologizar os comportamentos desviantes também faz atrelar ao diferente um juízo moral sobre a sua diferença, uma vez que associa a ela uma patologia, que culpabiliza individualmente o sujeito pela sua diferença. Especificamente no processo de medicalização dos problemas de aprendizagem, percebemos, recorrentemente, além do julgamento dos comportamentos inadequados, uma culpabilização do indivíduo e da família acerca de sua conduta diferente. Nesse sentido, indica-se a busca por tratamentos que atuariam no corpo (cirurgias, ministração de medicamentos, tratamentos e exames de alta complexidade) para prevenir, mapear e precisar os diagnósticos segundo a lógica médico-farmacológica.

Esse "processo de conferir uma aparência de problema de saúde a questões de outra natureza, geralmente de natureza social" recebeu o nome Medicalização (ANGELUCCI \& SOUZA, 2010, 
p. 9) por estudiosos sobre o tema (do Fórum de Medicalização e Despatologização da vida).

Segundo Lima \& Hashizume (2018), a medicalização fere os direitos humanos, quando o tratamento por medicamentos e psicofármacos compromete a segurança pessoal e o pleno desenvolvimento (cognitivo, físico e fisiológico) das crianças em fase escolar. Por estarem em desenvolvimento, não há nem diagnósticos conclusivos nem estudos sobre as ações futuras em médio e longo prazo no organismo dessas crianças. As autoras demonstram ainda como a medicação de crianças com problemas de aprendizagem tem se tornado um problema de saúde pública, restringindo os direitos humanos desses alunos, pois a medicação das dificuldades de aprendizagem exclui os alunos que possuem diferentes maneiras de aprender, sem respeito a sua dignidade e potencialidade.

\section{A medicalização: autores interlocutores}

Guarido (2010) é seguido por estudiosos sobre o tema, que entendem a medicalização como o processo de reduzir os problemas sociopolíticos a questões individuais.

Em momento algum estamos nos posicionando contra os diagnósticos, os tratamentos sofisticados em nível neurológico e os avanços da Medicina e da Farmacologia. Essa evolução de exames, tratamentos, drogas para tratar problemas fisicamente diagnosticados é importante para doenças restritas e cujos diagnósticos foram resultado de análises objetivamente identificadas por diferentes especialistas. Meira (2012) explicita que a crítica à medicalização não é direcionada à medicação de doenças e não busca contrariar as bases biológicas existentes no comportamento humano. Mas luta contra a tentativa de reduzir a subjetividade humana simplesmente a características orgânicas e é contrária à transformação de problemas inerentes à condição de ser humano e da vida em sintomas de doenças neurológicas. Porém, não é o que temos visto em grande parte da população escolar. Nas classes mais pobres, medianas e até 
altas, vemos o diagnóstico orgânico ser fechado por um profissional da saúde, que nem sempre tem acesso aos relatórios escolares, nutricionais, da assistência social e de outros aspectos importantes a serem considerados em crianças em desenvolvimento.

Estudos da epistemologia do conhecimento (FOUCAULT, 1977; LOPES\&FABRIS, 2017) nos invocam reflexões acerca do papel da Medicina na legitimação de discurso científico em prol de diferentes governamentalidades (modos de controle de funcionamento social). É inegável que, nos dias de hoje, o discurso médico impera sobre os demais saberes, por ter seu lugar legitimado social e politicamente. Nesse sentido, no que tange às problematizações da escola, percebemos que o discurso da Neurociências/ Pediatria/ Psiquiatria se alastra em "solo minado e carente", ocupando os discursos de educadores, gestores da educação, pais e alunos (LISBOA, 2014; 2016). Esse é o cenário em que o contexto da medicalização se impõe.

A medicalização faz que a medicina ocupe o centro das explicações sobre os problemas que fazem parte da experiência humana, e explicações sociais e políticas são ignoradas. Collares \& Moisés (2010, p. 72) enfatizam que "tratar questões sociais como se biológicas iguala o mundo da vida ao mundo da natureza. Isentam-se de responsabilidades todas as instâncias de poder, em cujas entranhas são gerados e perpetuados tais problemas".

Em outro trabalho que desenvolvemos (LIMA \& HASHIZUME, 2018), identificamos que, mesmo em casos em que de fato haja um problema biológico, é necessário cuidado, tendo em vista que o sujeito não pode ser reduzido a sua doença e a sociedade deve reconhecer e respeitar sua singularidade. No referido trabalho relatos demonstraram a preocupação de docentes, pais e gestão sobre o tema, reforçando a necessidade premente de mais estudos a respeito da questão. Lima \& Hashizume (2018) também ressaltam a importância de que a Escola e o Sistema de Saúde atuem disponibilizando informações que possibilitem à população fazer uma reflexão acerca do problema da medicalização, para que no futuro 
as famílias, alunos e professores estejam mais preparados para respeitar e trabalhar com as diferenças que se revelam na escola, assim a instituição escolar poderia atuar de forma preventiva.

Segundo Collares \& Moisés (2010), quando se trata de crianças e adolescentes, a medicalização da vida se revela na medicalização da educação, por meio da invenção das doenças do não -aprender. Assim, os grandes problemas do sistema educacional são entendidos como doenças que a medicina seria capaz de resolver, gerando uma significativa demanda por serviços médicos e ampliando a medicalização. Para Guarido (2010), no contexto escolar, o cientificismo assumiu um papel de autoridade em relação à educação das crianças. Tornou-se comum ver a apropriação do discurso médico-psicológico no cotidiano escolar, tanto na suspeita de um diagnóstico, quanto na demanda para que este se realize.

A medicalização da educação faz que problemas sociais relacionados à escolarização sejam evitados e, de acordo com Meira (2012), busca explicar o não aprender ou não se comportar de forma considerada adequada pela escola, pela presença de disfunções ou transtornos neurológicos.

Angelucci (2006) afirma que a grande quantidade de crianças nas escolas que se encontram enquadradas em inúmeras categorias de diagnósticos tem demonstrado o papel da escola em selecionar alguns e excluir outros. Há pouca reflexão a respeito da política educacional e das práticas escolares dela decorrentes como responsáveis pelo fracasso escolar. Então, para Meira (2012), há um processo de patologização dos problemas educacionais que justifica a manutenção da exclusão de muitas crianças que nunca conseguem se apropriar dos conteúdos escolares, mesmo permanecendo nas escolas por longos períodos. Tal patologização acaba por estigmatizar esses alunos com dificuldades escolares.

Goffman (1988) demonstra como o estigma transforma as relações sociais nas quais o indivíduo estigmatizado participa, excluindo-o socialmente e retirando sua humanidade: 
Um indivíduo que poderia ter sido facilmente recebido na relação social quotidiana possui um traço que pode-se impor a atenção e afastar aqueles que ele encontra, destruindo a possibilidade de atenção para outros atributos seus. Ele possui um estigma, uma característica diferente da que havíamos previsto (GOFFMAN, 1988, p. 8).

Segundo Collares \& Moisés (2010), muitos dos que recebem diagnósticos são indivíduos saudáveis que apresentam dificuldades nos processos de escolarização e nos modos de se comportar, indicando que possuem um modo de aprender distinto do padrão considerado normal.

Entendendo o aprendizado apenas "como efeito do funcionamento cerebral, da estimulação correta deste órgão que "nos governa', temos sua descrição reduzida a uma dimensão privada”, e se perde o entendimento da aprendizagem como um fenômeno que ocorre na relação entre seres humanos, portanto, fruto da ação humana e não apenas resultado de um organismo em bom funcionamento (GUARIDO, 2010, p. 37).

Tendo em vista essa realidade, Souza (2010) defende a necessidade de uma revisão estrutural do sistema educacional, para que haja uma melhor compreensão do porquê de tantas crianças permanecerem anos na escola sem conseguir aprender. Não se pode mais continuar atribuindo apenas ao organismo das crianças as causas do não aprendizado, o que é reforçado quando Guarido \& Moysés (2011) afirmam que, como a aprendizagem é um processo multideterminado, não seria adequado empregar tantos esforços para explicá-la, quase que exclusivamente, a partir de seu caráter biológico e individual. É necessário levar em consideração outros fatores como a qualidade da relação professor-aluno, as condições materiais e estruturais da escola e a existência de uma orientação pedagógica que dê o suporte adequado ao professor.

\section{Método}

Os dados foram coletados por meio de pesquisas bibliográficas nos Anais IV do Seminário Internacional "A Educação Medi- 
calizada: desver o mundo, perturbar os sentidos". Entre 165 trabalhos, foram selecionados 24 , entre trabalhos completos e resumos. No contato com os anais, verificou-se que eles contêm seis artigos completos e 18 resumos. Nos artigos analisados, todos tratam diretamente da medicalização de crianças e adolescentes no contexto atual. Entre eles, foram identificados 14 artigos que trazem intervenções concretas diante da problemática abordada; nove artigos que trazem reflexões teóricas acompanhadas de apontamentos da necessidade de construção de novas práticas interventivas frente à problemática; e 11 que trazem apenas estudos teórico-críticos (que foram identificados como de abordagem histórico-cultural, sociológica, abordagem crítica ou da Saúde mental coletiva/Saúde coletiva).

\section{Reflexões a partir da medicalização: pensando a inclusão e os direitos humanos}

Levando-se em conta que todos os trabalhos analisados foram submetidos a um seminário organizado por um grupo de pesquisadores que discutem medicalização dos problemas de aprendizagem, podemos afirmar que os pesquisadores coadunam com referenciais teóricos semelhantes, que analisam a patologização do fracasso escolar de forma significativamente semelhante.

Os estudos relacionados aos problemas de aprendizagem que enfatizam seu caráter multifacetado é quase a totalidade dos trabalhos analisados. Percebe-se um crescente interesse por essa temática, o debate sob referencial mais crítico se inicia em 2003, tendo os maiores índices de publicações a partir de 2012, promovendo críticas sobre as formas de viver e propondo um novo olhar no sentido da desmedicalizar a vida e a educação. A maioria dos artigos completos e dos resumos se refere especificamente à medicalização de crianças dando ênfase ao contexto escolar. Algumas medidas são essenciais para evitar a medicalização desenfreada que a pura oferta de consultas médicas e as prescrições comumente geram no cotidiano dos serviços de saúde.

Entre os 24 artigos analisados, a medicalização é discutida sob diferentes perspectivas: encontramos artigos que se queixa- 
vam da ausência de referencial teórico para análise das questões relacionadas à queixa escolar e medicalização, um trabalho usou o referencial teórico da Saúde Coletiva e da Saúde Mental Coletiva; um trabalho se auto-intitulou seguindo a abordagem crítica, que outros quatro trabalhos chamavam de abordagem histórico-cultural. Quatro trabalhos adotaram a Sociologia ou Sociologia da Educação como referencial teórico, utilizando autores da complexidade, como Foucault (1989) e, por fim, um trabalho fez uma análise mais pragmática e empírica acerca da realidade medicalizante, sem adotar um referencial teórico para a leitura dos resultados.

Em quase todos os trabalhos foi possível constatar que as caracterizações descritas nas fichas de encaminhamentos exibem significativa presença do discurso patologizante da subjetividade dos estudantes. É marcado também o discurso da associação do uso de medicamentos e/ou do controle da conduta do aluno com fins de se exponencializar suas performances escolares.

Os trabalhos analisados evidenciaram que a medicalização patologiza os problemas de aprendizagem dos alunos, sem considerar as desigualdades sociais nem conceber que o rendimento escolar dos alunos está intrinsecamente relacionado às origens sociais deles. $\mathrm{O}$ resultado disso é a manutenção da exclusão dos mais pobres dos espaços escolares, o que apenas ratifica o status quo social, em que tal parcela da população acaba por ser responsabilizada por seu fracasso.

Os trabalhos abordados na pesquisa se referem a visões que envolvem diferentes áreas do conhecimento, incluindo assistentes sociais, psicólogos, médicos, mas são raros os trabalhos realizados por educadores e professores da educação básica, o que parece apontar ainda uma visão de vanguarda apenas por profissionais especializados que atuam na educação, mas não os docentes, atores protagonistas nas relações de aprendizagem. O protagonismo dos docentes é necessário para a reversão da situação atualmente diagnosticada, tendo em vista a ampla abertura existente no meio escolar no sentido de acolher o discurso legitimado da medicina e da farmacologia, explicando os comportamentos dos alunos por 
meio de categorias nosológicas que transformam o que é incomum em patologia.

Tal associação impõe um juízo sobre a "anormalidade" dos diferentes. $\mathrm{O}$ preconceito vivido no ambiente escolar se alastra seja entre as crianças e suas famílias, seja no ambiente de professores, afetando o respeito e a dignidade das pessoas com deficiência ou com características incomuns ou consideradas inadequadas na escola. Por isso, acreditamos se tratar de uma questão de direitos humanos. Acessar a educação com dignidade, respeitando o direito de todos os alunos e crianças de terem acesso à educação é uma diretriz inquestionável sob a qual todos deveríamos estar submetidos. À medida que estudamos temas semelhantes a esse, que denunciam e problematizam práticas que reafirmam a manutenção de um modo de funcionamento hegemônico que exclui as diferenças, entendemos que estamos no rumo certo. Contribuir para minimizar tais práticas, que vão contra direitos básicos da população, nos coloca como multiplicadores de um debate importante que é recorrente no meio escolar.

Nosso artigo se propôs a analisar teórica e metodologicamente os resumos e trabalhos completos dos Anais do IV Seminário Internacional "A Educação Medicalizada", trazendo uma discussão sobre as relações entre medicalização, inclusão e os Direitos Humanos.

Faz-se importante, agora, recuperarmos o processo de controle pela governamentalidade. Além de outras formas de submissão do sujeito foram mapeadas técnicas de aprimoramento da aprendizagem e atenção, por exemplo, mas também novas formas de questionamento e de resistência. Os estudos realizados mostraram que ações podem romper com as linhas instituídas: práticas de matriciamento, cuidados além da consulta médica, práticas intersetoriais, grupais, educativas, políticas, sanitárias, em parceria com instituições culturais, políticas e educativas. Serão tais práticas as responsáveis pelas linhas de fuga, que poderão garantir o protagonismo na micropolítica do cotidiano educacional. Tais práticas micropolíticas romperão com o modo de produção de subjetividades serializadas, padronizadas e controladas. 
Numa análise mais ampla dos resultados que encontramos nos trabalhos analisados, percebemos que a medicalização altera a ordem na explicação dos problemas de aprendizagem, culpabilizando o aluno, os pais e o professor e, por sua vez, eximindo a escola e as políticas públicas da responsabilidade pela inclusão desses alunos que têm modos de aprendizado diferentes. Mas ao mesmo tempo, o discurso legitimado da Medicina e da Biologia, assim como o das Neurociências, ocupa o lugar de saber que a Pedagogia deveria ocupar. Portadores de um saber-fazer importante e necessário para a compreensão e para a mudança social do quadro escolar que se apresenta, os docentes precisam lançar mão de novas ferramentas que o coloquem numa posição de protagonismo e contrapoder ao discurso que está instituído. Ao afirmar que a causa do problema de aprendizagem está ligada às questões de saúde (doenças), genéticas e que precisam ser curadas/prevenidas para que a criança possa ser reinserida sã na escola está se invertendo a lógica democrática da escola - que deveria ser includente. Ao invés de se pensar o funcionamento escolar de modo que seja capaz de acolher a diversidade dos alunos e recebendo de forma colaborativa o aluno com deficiência, prevalece uma visão higienista e excludente. É irônico pensar esse processo, sendo praticado por educadores e especialistas que se presumem defensores da inclusão escolar. Podemos nos questionar se a "Inclusão" não tem se rendido a se tornar mais um especialismo que alimenta uma forte indústria de livros best-sellers, especialistas e processos judicializados intentando garantir os direitos a partir de ações individuais que nada mudam a realidade social aqui explicitada.

O que Foucault chama de biopoder deve ser entendido dentro de um modo de produção capitalista que produz e reproduz afetos, subjetividade, formas de vida que imperam na grande mídia, na moda e nas informações de ampla divulgação de massa. Quando se refere a uma espécie de "anatomo-política" ligada ao treinamento dos corpos voltada para a produção se insere num debate sobre a normalização na constituição dos seres vivos, ou seja, um tipo de política (con)formadora da vida e dos sujeitos. Tal conceito 
procura gerir o viver, maximizando os efeitos do poder disciplinar, fortemente presente nos séculos XVII e XVIII. Na segunda metade do século XVIII, uma nova forma de poder começa a se explicitar. Sem dispensar as técnicas disciplinares, a nova prática de controle elege outros objetos de aplicação: ao invés de atuar em instituições fechadas e nos corpos, a estratégia da biopolítica maximiza os esforços disciplinares por se alastrar pelos espaços abertos, muito além das instituições, e dirigir-se ao homem como ser vivo, como espécie humana: o foco agora é a população (TEDESCO \& NASCIMENTO, 2009). Questões como natalidade, longevidade, mortalidade são trabalhadas em dimensões estatísticas. O corpo se mantém como matéria do poder, mas como "corpo múltiplo". A população emerge como problema científico e político (FOUCAULT, 1977). E ao problematizar fenômenos populacionais, estabelecem-se generalizações, normalizações e níveis globais de equilíbrio. Nessa nova forma de poder, a ação é no sentido de produzir subjetividades dentro de uma regularidade, buscando a homogeneização por meio de padrões gerais de condutas sociais.

A biopolítica engloba um conjunto de biopoderes locais, isto é, como uma nova tipologia de relações de poder que se aplicam à vida (FOUCAULT, 1997). Tais modos de poder se alastram, utilizando instituições como a escola, o hospital, além de discursos socialmente legitimados como o do Direito, da Medicina e da Neurociências, que têm como objetivo subjacente o controle dos corpos: por detrás de uma preocupação com o biológico, fisiológico e psicológico, o esquadrinhamento do corpo tem fins de controle (FUGANTI, 1990; 2001). Controlam, pois, o pensamento, os modos de comportamento, enfim, a vida. Tal visão é engendrada a partir do "consentimento da sociedade, que delega à medicina a tarefa de normatizar, legislar e vigiar a vida" (COLLARES, MOYSÉS, 2008, p. 1).

Normatizar fala do controle e da regulação do estado sobre a vida de cada um e da população. Tal processo intenta controlar os comportamentos individuais, mas também os forjados no interior das comunidades. Tais conceitos de normalidade são flutuantes 
dependendo dos momentos históricos e da sociedade estudada. Por isso, a importância de não considerarmos que sejam naturais. Historicamente, quando a normalização dos anormais é tratada como uma prática necessária aos governos, o Estado estabelece ações com foco no corpo dos indivíduos, visando tirar de cada um a potência para o governamento. Nesse sentido, a disciplina é uma norma universal, referência que busca agir sobre cada indivíduo (LOPES, 2017).

Nos tempos modernos, a escola, mais do que qualquer instituição total, se encarrega de operar essas individualizações disciplinares, produzindo e engendrando novas subjetividades (autocontroladas), trazendo uma nova conformação e manutenção de normas. Nesse sentido, escolas, manicômios, hospitais, seminários passam a se encarregar de agir disciplinando os indivíduos e a sociedade. A produtiva vigilância no controle dos indivíduos permitiu pensar a escola como um lócus privilegiado responsável pela inclusão e pela normalização, cada vez mais atualizados pelos movimentos que discutem o tema. Atuando no campo simbólico e material, há um apelo grande em relação a tudo o que se relaciona à inclusão. Quando nos referimos aos diferentes diagnósticos e transtornos que identificamos nas escolas devemos refletir em que medida a temática da inclusão é fundamental para contextualizarmos econômica e politicamente o tempo e o contexto em que ela emerge. Compreender, dentro desse cenário, que não há lugar para todos é aceitarmos que sempre haverá parcelas da população que serão excluídas, já que esta não é produtiva nem se adequa às demandas normativas e normais de funcionamento social. Nesse sentido, valores como a solidariedade, bem comum, coletividade são deixados de lado em prol de um discurso produtivista que visa a manutenção de um sistema já existente (LOPES, 2017).

Objetificar o sujeito - aprendente - como mais uma forma de investimento é uma consequência da visão pragmática sobre o sujeito, que cria um mercado de grupos que devem ser incluídos: determinadas condições específicas dos indivíduos, marcas identitárias, de gênero, étnico-raciais, linguísticas, condições em que se 
somam o portador de TDAH, TEA, TOD, entre outros. Cria-se, portanto, um mercado determinado pela competição desses grupos, que lutam pelo reconhecimento de seus direitos dentro de seus funcionamentos. Quando tal reconhecimento não ocorre, acredita-se que se deve ao fato de não ter feito os investimentos certos nos momentos certos, numa parceria entre Mercado e Estado, que veem os indivíduos como capitais. Dentro da racionalidade governamental neoliberal, o sujeito necessita de sua autopromoção, sem necessariamente considerar interesses comuns. Nessa corrida pela valorização de seu grupo, o homem passará a aprender para toda a vida como se comportar diante dos desafios colocados cotidianamente no diálogo com a diversidade. Nessa visão neoliberal, o indivíduo passa a ver o outro que não concorre consigo de forma tolerante, mas competindo com o outro grupo que o ameaça. $\mathrm{O}$ grande risco dessa visão é nos deixarmos vencer por necessidades egoístas, paixões sociais, despolitizando o sujeito e fazendo-o se dirigir apenas à sua satisfação pessoal.

Frente a esse cenário, devemos pensar as zonas de inclusão/exclusão propostas por Castel (1997), em que este propõe que todos, incluídos e excluídos se encontram numa situação de insegurança. Nesse sentido, a inclusão, em nosso entendimento, pode ser vista como estratégia de Estado para desenvolver na população uma subjetividade inclusiva. Assim, vemos o grupo dos TDAH, o grupo dos autistas, o grupo das pessoas com deficiência em geral. Lopes (2017) propõe o termo in/excluído para abarcar a ambiguidade e ambivalência existente entre os termos de integração e inclusão para continuarmos as lutas políticas, mas também as pesquisas no campo da educação e saúde.

Pensar apenas nas situações de violações de direitos humanos, como os alunos com deficiência ou outros diagnósticos sem laudos fechados, é pouco. Precisamos pensar o cidadão de forma mais ampla, para que possamos refletir nas variações da vida que a biopolítica tenta capturar. 


\section{Considerações finais}

Vivemos numa sociedade em que tudo que é diferente ou foge à normalidade é transformado em doença, em problema biológico e individual. Nosso artigo tratou do termo medicalização dos problemas de aprendizagem e seus desdobramentos para se pensar a inclusão e os Direitos Humanos de acesso à educação. $\mathrm{Na}$ ânsia pela padronização de comportamentos e modos de ser, os diferentes são vistos como indesejáveis e passíveis de cura, que terão nos profissionais da área da saúde seus salvadores.

Num momento social de bastante intolerância do diferente, faz-se necessário dispositivos de suporte ancorados em uma lógica mais coletiva e que envolva toda a comunidade escolar, com investimento permanente em mecanismos que capacitem a comunidade em relação a seus direitos e deveres e ser protagonista desse processo. Se conseguirmos, por meio da educação em direitos, almejando a cultura da paz, ao formar nas séries iniciais novas gerações de docentes mais sensíveis em relação aos diferentes modos de aprendizado e funcionamento, modifica-se a visão patologizante a respeito dos alunos que fogem à média. Gestão, professores e comunidade escolar devem construir um olhar diferente sobre o uso de psicofármacos nas crianças, e que possibilite acesso a informações acerca do uso abusivo a toda a comunidade escolar.

O Movimento da Medicalização/Despatologização dos problemas de aprendizagem, dentro desse cenário, possibilita o debate coletivo em que se constroem novas formas de enfrentar as dificuldades de aprendizagem que surgem na escola; é na escola, lócus privilegiado de debates e nos projetos junto a pesquisadores, como nós, que podemos frutificar o protagonismo de alunos, docentes, pais e comunidade escolar do entorno.

Desse modo, podemos garantir que os Direitos Humanos estarão garantidos no acesso à escola e à formação do futuro cidadão. Promover o protagonismo e autonomia aos educandos, público-alvo da educação especial e com dificuldades/transtornos de aprendizagem, por meio de um projeto pedagógico realmente in- 
clusivo, é atuar na saúde desses aprendizes. O desafio desse projeto transcende as definições citadas sobre o protagonismo, pois requer promover a autonomia dos atores escolares dentro da proposta. No que tange ao papel de pais, estes devem ser incentivados a participar de um processo de ressignificação de si, da sua dificuldade, das políticas públicas que possam estar disponíveis a eles. Isso requer um trabalho para elevar a autoestima dos alunos, quase sempre alvos da visão normatizante.

Nessa ampla discussão sobre saúde, direitos humanos e acesso à educação, resgatar esse sujeito como aprendente, capaz, potente e futuro cidadão é fundamental para construir uma visão saudável e inclusiva sobre o aluno com necessidades especiais. $\mathrm{O}$ cuidado com o olhar, agora menos patologizante, também torna mais rigorosa a categorização e o cuidado a esse alunado. Cabe a nós, professores-pesquisadores, problematizarmos o ritmo frenético produtivo que se impõe às pessoas, na vida em geral, o que tem trazido consequências preocupantes nos processos educacionais, que estão sendo chamados para ingressarem na lógica produtiva do capitalismo neoliberal.

Um debate ético-estético político é necessário, pois o tema esbarra em decisões, rede de forças e poderes e contrapoderes na gestão escolar. O microcosmo da escola é representativo de um turbilhão de interesses produtivos (econômicos, sociais e políticos) sob os quais nos encontramos chamados nas nossas práticas cotidianas.

\section{Referências}

ANGELUCCI, C. B. A inclusão escolar de pessoas com necessidades especiais na rede estadual de São Paulo: a dissimulação da exclusão. In: L. S. Viégas \& B. Angelucci (Orgs.). Políticas públicas em Educação: uma análise crítica a partir da Psicologia Escolar. São Paulo: Casa do Psicólogo, 2006, p. 187-228.

ANGELUCCI, C. B.; SOUZA, B. P. Apresentação. In: Medicalização de crianças e adolescentes: conflitos silenciados pela redução de questões sociais a doenças de indivíduos (Orgs.). Conselho Regional de Psicologia de São Paulo; Grupo Interinstitucional Queixa Escolar. São Paulo: Casa do Psicólogo, 2010. 
ASBAHR, Flávia da Silva Ferreira; VIEGAS, L. S.; ANGELUCCI, C. B. Apresentação. In: Viegas, Lygia de Sousa; Angelucci, Carla Biancha (Org.). Políticas públicas em educação: uma análise crítica a partir da psicologia escolar, 1. ed. São Paulo: Casa do Psicólogo, 2006, p. 9-23.

CAMPOS, Elisabete Ferreira Esteves. A formação de pesquisadores iniciantes: Contribuições da pesquisa participante. In: FURLIN, Marcelo; COELHO, Patrícia Farias (Org.). Educação em Pauta: Múltiplos Olhares. São Bernardo do Campo: Universidade Metodista de São Paulo, 2018, p. 87-106.

CARDOSO, Daniela de Figueiredo Moitinho; HASHIZUME, Cristina Miyuki. Cadernos de Educação, v. 17, n. 35, jul./dez. 2018. Medicalização na educação: refletindo sobre seu desdobramento na saúde pública e direitos humanos. Disponível em: https://www.metodista.br/revistas/revistas-ims/index.php/cadernosdeeducacao/article/view/9342/6591 Acesso em: 21 de nov. 2019.

COLLARES, C. A. L.; MOYSÉS, M. A. A. Preconceitos no cotidiano escolar: a medicalização do processo ensino-aprendizagem. In: CONSELHO REGIONAL DE PSICOLOGIA DE SÃO PAULO (Org.). Medicalização de crianças e adolescentes: conflitos silenciados pela redução de questões sociais a doença de indivíduos. São Paulo: Casa do Psicólogo, 2010, p. 193-213.

. Dislexia e TDAH: uma análise a partir da Ciência Médica. In: CONSELHO REGIONAL DE PSICOLOGIA, Grupo Interinstitucional Queixa Escolar (Orgs.). Medicalização de crianças e adolescentes: conflitos silenciados pela redução de questões sociais a doenças de indivíduos (Orgs.). Conselho Regional de Psicologia de São Paulo; Grupo Interinstitucional Queixa Escolar. São Paulo: Casa do Psicólogo, 2010.

FIDALGO, S. S. A linguagem da exclusão e inclusão social na escola. São Paulo: UNIFESP, 2018.

FIRBIDA, Fabíola Batista Gomes. A CRÍTICA DA MEDICALIZAÇÃO DA APRENDIZAGEM A LUZ DA PSICOLOGIA HISTÓRICO-CULTURAL. IV SEMINÁRIO INTERNACIONAL "A EDUCAÇÃO MEDICALIZADA: DESVER O MUNDO, PERTURBAR OS SENTIDOS”, [s. l.], 2014.

FOUCAULT, M. O nascimento da clínica. Rio de Janeiro: Forense, 1977.

Vigiar e punir. Rio de Janeiro: Paz e Terra, 1997.

Microfísica do poder. Rio de Janeiro: Graal, 1989. 
FUGANTI, Luiz. A Ética Como Potência e a Moral Como Servidão. São Paulo: 2001 (Digitado).

. Saúde, Desejo e Pensamento. Saúde e Loucura, n. 2. São Paulo: Ed. Hucitec, p. 19-82, 1990.

GOFFMAN, Erving. Estigma: notas sobre a manipulação da identidade deteriorada. Tradução de Márcia Bandeira de Mello Leite Nunes, 4. ed. Rio de Janeiro: LCT, 1988.

GUARIDO, J.; MOYSÉS, M. A. A. Um Panorama Nacional dos estudos sobre a medicalização da aprendizagem de crianças em idade escolar. In: CONSELHO REGIONAL DE PSICOLOGIA DE SÃO PAULO. Grupo Interinstitucional Queixa Escolar. Medicalização de crianças e adolescentes: conflitos silenciados pela redução de questões sociais a doenças de indivíduos. São Paulo: Casa do Psicólogo, 2010.

GUARIDO, R. A biologização da vida e algumas implicações do discurso médico sobre a educação. In: CONSELHO REGIONAL DE PSICOLOGIA DE SÃO PAULO, Grupo Interinstitucional Queixa Escolar (Orgs.). Medicalização de crianças e adolescentes: conflitos silenciados pela redução de questões sociais a doenças de indivíduos (Orgs.). Conselho Regional de Psicologia de São Paulo; Grupo Interinstitucional Queixa Escolar. São Paulo: Casa do Psicólogo, 2010, p. 27-39.

HASHIZUME, C. M. DIETRICH, A. M. (Orgs). Direitos Humanos no chão da escola. Santo André: UFABC, 2017.

LAKATOS, Eva Maria; MARCONI, Marina de Andrade. Fundamentos de metodologia científica, 5. ed. São Paulo: Atlas, 2003.

LEMOS, F. C. S.; GALINDO, Dolores; Piani, P. P. F. Pesquisa-intervenção e direitos humanos. Apontamentos arqueológicos e genealógicos na análise de documentos. Polis e Psique, v. 5, p. 38-48, 2015.

LISBOA, F. S. O Cérebro vai a escola: aproximações da Neuropsicologia à Educação no Brasil. São Paulo: PACO, 2016.

O Cérebro vai a escola: aproximações da Neuropsicologia à Educação no Brasil. Programa de Pós-Graduação em Saúde Coletiva. UERJ, 2014. Disponível em: http://www.bdtd.uerj.br/tde_busca/arquivo.php?codArquivo=6946. Acesso em: 16 nov. 2019 
LOPES, M. C.; FABRIS, E. H. Inclusão e educação. Belo Horizonte: Autêntica, 2017.

MEIRA, Marisa Eugênia Melillo. Para uma crítica da medicalização na educação. Psicol. Esc. Educ., Maringá, v. 16, n. 1, p. 136-142, 2012. Disponível em: http://www.scielo.br/scielo.php?script=sci_arttext\&pid=S14 13-85572012000100014\&lng=en\&nrm=iso Acesso em: 9 ago. 2018.

NOZU, W. C. S.; LONGO, M. P.; BRUNO, M. M. G. Direitos humanos e inclusão: discursos e práticas sociais. EDUFMS: Campo Grande, 2014.

ROCHA, Marisa Lopes da and AGUIAR, Katia Faria de. Pesquisa-intervenção e a produção de novas análises. Psicol. cienc. prof. [on-line], 2003, v. 23, n. 4, p. 64-73. ISSN 1414-9893. http://dx.doi.org/10.1590/S1414-98932003000400010.

SEMINÁRIO INTERNACIONAL "A EDUCAÇÃO MEDICALIZADA: DESVER O MUNDO, PERTURBAR OS SENTIDOS”, IV, 2015, Bahia. ANAIS [...]. [S. 1.: s. n.], 2016. Disponível em: http://anais.medicalizacao.org.br/index.php/ educacaomedicalizada/issue/view/2. Acesso em: 22 nov. 2019.

SOUZA, Marilene Proença Rebello de. Retornando à patologia para justificar a não aprendizagem escolar: a medicalização e o diagnóstico de transtornos de aprendizagem em tempos de neoliberalismo. In: Conselho Regional de Psicologia de São Paulo \& Grupo Interinstitucional Queixa Escolar (Orgs.). Medicalização de crianças e adolescentes: conflitos silenciados pela redução de questões sociais a doenças de indivíduos (p. 57-67). São Paulo: Casa do Psicólogo, 2010. 